\title{
Sintesis Carbon Nanotubes (CNT) Berbasis Bahan Alam Limbah Tempurung Kelapa dan Aplikasinya dalam Pembuatan Polimer Komposit Polimida-CNT: Review
}

\section{Synthesis of Coconut-Shell Waste-based Carbon nanotubes (CNT) and Its Application in Polymer Composite Polyimide-CNT Fabrication: Review}

\author{
Dini Deviana Saputri dan Teguh Endah Saraswati*
}

\author{
Departemen Kimia, Fakultas Matematika dan Ilmu Pengetahuan Alam, \\ Universitas Sebelas Maret
}

J1. Ir. Sutami No. 36A, Kentingan, Surakarta, Jawa Tengah, Indonesia Indonesia, 57126

*Email: teguh@mipa.uns.ac.id

\begin{abstract}
Abstrak. Carbon nanotubes (CNT) menjadi salah satu material unggul teknologi nano yang membawa banyak keuntungan karena memiliki sifat kimia dan mekanik yang baik. Hal ini menjadikan CNT dimanfaatkan di berbagai aplikasi nano-device ataupun material komposit. Beberapa metode yang sering digunakan untuk menumbuhkan CNT adalah deposisi uap kimia (Chemical Vapor Deposition), laser ablasi dan arc discharge. Kebanyakan sumber prekursor karbon dalam sintesis CNT diambil dari bahan bakar fosil yang memiliki kelemahan bahan tidak bisa diperbaharui dan menghabiskan biaya yang mahal. Limbah bahan alam atau hasil biomassa dapat menjadi alternatif bahan baku pembuatan CNT yang membawa keunggulan biaya murah, ketersediaan melimpah, dan hemat energi, contohnya seperti limbah tempurung kelapa yang mengandung unsur karbon tinggi. Tempurung kelapa telah dilaporkan sebagai salah satu bahan baku potensial produksi CNT. Aplikasi CNT dalam polimer komposit contohnya penggabungan dengan polimida. Keunggulan polimida adalah sifat mekaniknya yang sangat baik, stabilitas termal, dan ketahanan kimia. Namun, polimida memiliki kelemahan dalam konduktivitas termal yang rendah. Penambahan CNT ke dalam polimida dapat meningkatkan konduktivitas termal sehingga meningkatkan kinerja polimer tersebut.
\end{abstract}

Kata Kunci: Carbon nanotubes (CNT), Tempurung Kelapa, Polimida

Abstract. Carbon nanotubes (CNTs) have become one of the excellent materials for nanotechnology which brings many advantages because of their good chemical and mechanical properties, inducing CNTs to be used in various nano-device applications or composite materials. Some of the methods commonly used to grow CNTs are chemical vapor deposition, laser ablation, and arc discharge. Most sources of carbon precursors in CNTs synthesis are taken from fossil fuels which have the disadvantages of non-renewable materials and high cost. Natural waste or biomass products can be an alternative raw material for CNTs production which brings the advantages of low cost, abundant availability, and energy-saving, for example, such as coconut shell waste which contains high carbon elements. Coconut shell has been reported as one of the potential raw materials for CNT production. CNT applications in composite polymers are for example collaboration with polyimides. The advantages of polyimides are their excellent mechanical properties and chemical resistance. However, polyimides have a disadvantage in their low thermal conductivity. The addition of CNT into polyimides can increase its thermal conductivity enhancing polyimide performance.

Keywords: carbon nanotubes, coconut shell waste, polyimide 


\section{Pendahuluan}

Karbon sebagai unsur ke-empat dengan kelimpahan terbanyak di alam, menjadikannya banyak dimanfaatkan atau diolah pada berbagai bidang aplikasi [1]. Atom-atom karbon berukuran kecil, membentuk nanostruktur yang berdiameter 1 hingga 100 nanometer [2]. Karbon sendiri terbagi menjadi beberapa bentuk alotrop (elemen karbon yang sama, namun saling berikatan dengan cara yang berbeda) [3]. Alotrop karbon dikategorikan berdasarkan susunan strukturnya menjadi non-kristalin (contohnya : karbon aktif) dan kristalin (contohnya : intan, grafit, fullerene dan nanotube) [4]. Alotrop karbon menghasilkan morfologi yang berbeda-beda sehingga aplikasinya dapat berkembang luas, seperti adsorben, katalis pendukung, teknologi pemisahan, penyimpanan gas, elektroda baterai, aplikasi sel bahan bakar dan sel biologis [5]. Kelebihan yang dibawa karbon berupa segi sifat kimia yaitu titik leleh dan titik sublimasi tinggi, mudah dibentuk untuk membuat senyawa beragam karena karbon punya kemampuan mengikat rantai panjang antar karbon.

Diantara alotrop karbon lainnya, Carbon nanotubes (CNT) mampu menjadi salah satu material unggul teknologi nano yang membawa banyak keuntungan. CNT dikenal dengan struktur antar karbon membentuk heksagonal dengan ikatan $\mathrm{C}-\mathrm{C}$ berhibridisasi sp2. CNT punya kelebihan berupa sifat mekanik yang baik, seperti modulus tinggi, kekuatan yang baik, dan fleksibilitas tinggi. Hal ini menjadikan CNT banyak dimanfaatkan di berbagai aplikasi nano-devices dan material komposit [6]. Potensi CNT ini juga dapat disalurkan ke dalam aplikasi elektroda peralatan display, material komposit, transistor, pendeteksi gas dan penyimpan hidrogen [7].

CNT ditemukan pertama kali oleh Sumio Iijima, seorang ilmuwan dari Jepang pada tahun 1991 melalui metode arc discharge dalam sintesis fullerene [8,9]. Pesatnya perkembangan CNT karena kemampuannya dalam pengontrolan posisi suatu objek dengan baik, seperti pada aplikasi alat field-electron emitter [10]. Teknologi nano merupakan suatu teknologi penghasil material berukuran lebih kecil dari satu mikrometer (sekitar nanometer). Kelebihan dari teknologi nano dibandingkan dengan material berukuran besar yaitu bahan nano bisa dimanipulasi, dikontrol dan dibentuk pada skala atom atau molekul menjadi produk material. Hal ini juga berpengaruh terhadap peningkatan sifat fisik dan kimia material tersebut [11].

Carbon nanotubes diklasifikasikan menjadi dua jenis berdasarkan jumlah lapisan/ lembaran grafit yang mengelilinginya membentuk silinder, yaitu Single-Walled Carbon nanotubes (SWCNT) dan MultiWalled Carbon nanotubes (MWCNT). SWCNT berarti hanya terdiri satu sisi dinding silinder lapisan grafit. Sedangkan, MWCNT berarti terdiri dari beberapa gabungan SWCNT dengan diameter berbeda. Antara SWCNT dan MWCNT pun, memiliki sifat kimia dan fisika yang berbeda [12]. Selain itu, struktur karbon dari CNT juga dapat dibedakan menjadi zigzag, armchair atau chiral [13].

Carbon nanotubes biasanya disintesis dari bahan hidrokarbon sebagai prekursor karbon. Bahanbahan yang sering digunakan dalam sintesis $\mathrm{CNT}$, seperti alkohol, metanol, metana $\left(\mathrm{CH}_{4}\right)$, etilen $\left(\mathrm{C}_{2} \mathrm{H}_{4}\right)$, asetilen $\left(\mathrm{C}_{2} \mathrm{H}_{2}\right)$, propana $\left(\mathrm{C}_{3} \mathrm{H}_{8}\right)$, atau sikloheksana $\left(\mathrm{C}_{6} \mathrm{H}_{12}\right)$ [14]. Dalam pertumbuhan $\mathrm{CNT}$, prekursor karbon bersama campuran gas lain yang masuk akan berinteraksi dengan substrat dan katalis, sehingga dihasilkan gas sisa yang akan divakum dan hasil padatan CNT [15]. Parameter yang mempengaruhi keberhasilan pertumbuhan CNT adalah katalis, temperatur sistem, campuran gas prekursor dan gas pembawa serta tekanan gas [16]. Sayangnya, kebanyakan sumber prekursor karbon dalam sintesis CNT berasal dari bahan bakar fosil yang memiliki kelemahan tidak bisa diperbaharui dan menghabiskan biaya yang mahal [14].

Sumber karbon yang biasa digunakan diambil dari produk minyak bumi dan batubara. Jika digunakan berkelanjutan, hal ini dapat menimbulkan masalah, seperti kehabisan energi dan krisis lingkungan. Maka dari itu, perlu dicari sumber bahan baku karbon yang ramah lingkungan, berbiaya rendah dan dapat diperbaharui [17]. Seiring dengan berkembangnya produksi aplikasi CNT berskala besar, tentu saja bahan baku dengan biaya tinggi akan berimbas pada harga produk akhir yang dijual di pasaran [18]. 
Limbah bahan alam atau hasil biomassa dapat menjadi alternatif bahan baku pembuatan CNT yang memiliki keunggulan biaya murah untuk produksi skala besar, ketersediaan melimpah, dapat diperbaharui dan hemat energi. Parameter suatu bahan alam dapat digunakan sebagai pengganti bahan baku sintesis nanokarbon adalah memiliki kandungan karbon tinggi [18]. Contoh penggunaan prekursor bahan alam yang telah dilakukan, seperti minyak kamper, minyak kayu putih, minyak terpentin, limbah minyak goreng sawit, minyak sawit, minyak kelapa, dan minyak jarak. [19]. Salah satu bahan limbah yang telah dilaporkan dapat dimanfaatkan sebagai bahan baku prekursor karbon sintesis CNT adalah limbah tempurung kelapa.

\section{Pembahasan}

\subsection{Jenis Metode Sintesis Carbon Nanotubes (CNT)}

Berbagai metode yang telah diteliti dapat dilakukan untuk menumbuhkan CNT, seperti arc discharge, laser ablasi dan deposisi uap kimia (Chemical Vapor Deposition, CVD) [20]. Metode arc discharge dihasilkan dengan menerapkan DC antara anoda grafit dan katoda grafit dalam chamber berisi Helium. Anoda berupa prekursor karbon untuk sintesis CNT, sedangkan katoda terdiri dari batang grafit. Busur arc berupa plasma bersuhu tinggi $(>4000 \mathrm{~K})$. Gradien suhu mendorong uap menuju katoda. Setelah busur arc dimatikan, CNT akan diperoleh pada katoda. Metode ini memiliki keuntungan produksi CNT yang cepat dengan sedikit kecacatan. Namun, metode ini memiliki kemampuan pengendalian yang buruk dan produktivitas yang rendah. Selanjutnya, metode laser ablasi yaitu metode sintesis CNT pada suhu tinggi $\left(1200^{\circ} \mathrm{C}\right)$. Laser diterapkan untuk menguapkan karbon. Katalis yang diuapkan selama laser ablasi berfungsi mencegah partikel karbon terserap ke struktur ruang. Hasil CNT yang disintesis dengan metode laser ablasi memiliki kemurnian lebih tinggi daripada yang dihasilkan dengan arc discharge, tetapi hasil produktivitas CNT-nya rendah [21]

Dibandingkan dengan metode lain, deposisi uap kimia (CVD) merupakan metode yang paling menguntungkan di masa depan [22]. Pengotor hasil sintesis CNT dapat berfmanfaat memberi sifat kekuatan aditif mekanis atau magnetik pada CNT [23]. Liu et al. [24] melaporkan bahwa logam katalis yang biasa digunakan dalam metode CVD adalah besi (Fe), nikel (Ni), dan kobalt (Co), molibdenum (Mo), tembaga $(\mathrm{Cu})$, magnesium $(\mathrm{Mg})$, kromium $(\mathrm{Cr})$ dan jenis logam transisi lainnya. Metode CVD memiliki prinsip yaitu mengeluarkan semua gas yang berada di dalam chamber, kecuali gas pengendap. Kemudian, gas prekursor dibawa ke dalam quartz tube dan dipanaskan oleh penghasil energi. Reaksi akan dimulai ketika mencapai energi yang dibutuhkan. Karbon akan diendapkan ke dalam substrat, hidrogen sebagai gas residu akan dikeluarkan melalui pompa vakum [8]. CVD memiliki keunggulan biaya yang rendah, produktivitas tinggi, skalabilitas tinggi dan mudah dikontrol [25].Selain itu, CVD dapat digunakan untuk substrat yang terpola [26].

\subsection{Pemanfaatan Limbah Tempurung Kelapa Sebagai Bahan Baku Alternatif Sintesis CNT}

Tempurung atau batok kelapa sebagai hasil pengolahan buah kelapa sawit di beberapa negara tropis berujung menjadi limbah. Hal ini dapat dimanfaatkan sebagai bahan baku arang karbon bernilai ekonomis [27]. Tempurung kelapa sebagai salah satu adsorben berkarbon, memiliki sifat unik seperti kadar abu rendah, struktur berpori yang dapat dioptimalkan, dan luas permukaan internal yang besar [28]. Tempurung kelapa dilaporkan menjadi bahan baku potensial untuk pertumbuhan CNT [29].

Menurut Rampe et al. [30], hasil pembakaran tempurung kelapa dalam fabrikasi CNT memiliki struktur mirip grafit. Untuk mendapatkan karbon dari arang tempurung kelapa, dilakukan pemanasan pada suhu tinggi hingga $600-1000^{\circ} \mathrm{C}$ agar pengotor menguap. Selama proses pemanasan, semua bahan nonkarbon harus dihilangkan untuk membentuk karbon murni yang berkaitan dalam menyusun strukturnya [31, 32]. Proses pemanasan tempurung kelapa terdiri dari tahap pertama yaitu karbonisasi, sampel karbon menjadi kokas. Serta, tahap kedua adalah tahap grafitisasi, kokas diubah menjadi karbon grafit. 
Araga dan Sharma [26] melaporkan percobaan pembuatan CNT dari arang tempurung kelapa sebagai bahan baku. Tahapan pengolahan tempurung kelapa dilakukan melalui pirolisis. Tempurung kelapa yang telah dikumpulkan, lalu dihancurkan menjadi potongan-potongan kecil. Potongan yang hancur dipanaskan dalam oven. Tabung tungku lalu dialiri dengan nitrogen, dilanjutkan proses pirolisis untuk mendapatkan arang tempurung kelapa. Proses sintesis CNT dilakukan dengan metode Radio Frequency PECVD (RF-PECVD) dengan menumbuhkan CNT di atas permukaan sampel arang tempurung kelapa.

Berdasarkan eksperimen yang dilakukan Kang et al. [33], dikembangkan metode quenching dalam sintesis CNT dari tempurung kelapa. Metode ini dipilih karena aman, murah, dan dapat diterapkan pada skala industri. Langkah yang dilakukan yaitu dengan membakar limbah tempurung kelapa yang dibakar, dipanaskan hingga $700^{\circ} \mathrm{C}$. Setelah suhu mencapai $700^{\circ} \mathrm{C}$, grafit yang berwarna kemerahan segera diambil dan dicelupkan ke dalam air dingin, kemudian dibiarkan selama beberapa jam. Pemanasan dilakukan dengan oven hingga suhu $60^{\circ} \mathrm{C}$ selama 24 jam untuk menguapkan pelarut air. Karbon hasil sintesis berupa serbuk hitam yang kemudian dikarakterisasi.

Adewumi et al. [34] melakukan sintesis CNT dari serat kelapa. Sama seperti tahapan lainnya, serat kelapa dibersihkan, dipotong kecil-kecil dan dikeringkan. Serat kelapa (carbon fibre) dimasukkan ke dalam tabung kuarsa tahan panas dan ditempatkan dalam tungku tabung horizontal. Pengaruh suhu terhadap perkembangan nanomaterial dipelajari dengan mengolah karbon aktif yang berasal dari serat kelapa dengan uap etanol pada suhu tinggi tertentu. Aerosol dihasilkan dari etanol menggunakan pelembab udara ultrasonik yang beroperasi pada $50 \mathrm{~Hz}$. Gas argon dialirkan melalui kabut aerosol dan fungsinya menciptakan atmosfir inert untuk reaksi serta untuk mengangkut tetesan aerosol ke dalam ruang reaktor. Garis aerosol ditutup pada suhu yang diinginkan, dan gas argon dibiarkan mengalir sehingga sistem menjadi dingin.

\subsection{Aplikasi Pembuatan Polimer Komposit Polimida-CNT}

Polimida (PI) merupakan polimer yang tersusun atas monomer imida dengan kelebihan memiliki sifat mekaniknya yang sangat baik, stabilitas termal, dan ketahanan kimia karena polimida termasuk polimer yang mengandung cincin aromatik pada backbone [35]. Gaya antarmolekul yang kuat antara rantai polimer dimiliki polimida dan kekakuan unit berulang bagian aromatik dalam struktur heterosiklik. Sehingga, pelapis komposit PI dapat dimanfaatkan dalam sel surya, antena pesawat ruang angkasa, LED, dan sebagian besar pada bagian mekanis yang bergerak seperti roda gigi, bantalan dan bushing [36].

Dengan sifatnya tersebut, polimida menawarkan potensi besar baik di bidang aplikasi elektronik, membran, bahan isolasi, atau industri dirgantara. Sayangnya, polimida juga memiliki kelemahan yaitu konduktivitas termal yang sangat rendah $(0,1 \mathrm{~W} / \mathrm{mK})$ sehingga tidak dapat memenuhi persyaratan termal produk elektronik. Hal ini membatasi aplikasinya dalam bidang mikroelektronika dan ruang angkasa canggih [37].

Solusi dari kelemahan polimida tersebut dengan menambahkan pengisi konduktivitas termal tinggi untuk meningkatkan kinerja termal dari polimida. Bahan pengisi anorganik yang dapat digunakan karena memiliki konduktivitas termal tinggi adalah karbon hitam, alumina $\left(\mathrm{Al}_{2} \mathrm{O}_{3}\right)$, aluminium nitrida $(\mathrm{AlN})$, silika $\left(\mathrm{SiO}_{2}\right)$, titanium dioksida $\left(\mathrm{TiO}_{2}\right)$, silikon karbida $(\mathrm{SiC})$, silikon nitrida $\left(\mathrm{Si}_{3} \mathrm{~N}_{4}\right)$, boron nitrida $(\mathrm{BN})$, dan seng oksida ( $\mathrm{ZnO})$. Selain itu, material yang dapat digunakan sebagai pengisi anorganik yaitu CNT yang mempunyai konduktivitas listrik tinggi, konduktivitas termal tinggi $(3500 \mathrm{~W} / \mathrm{mK})$, modulus young tinggi $(0,9 \mathrm{TPa})$ dan kekuatan tarik (150 GPa), serta sifat optik yang sangat baik [38]. Elektron di dalam CNT tidak mudah tersebar karena diameternya yang sangat kecil dan rasio panjang terhadap diameter yang sangat besar. Hal ini juga menjadi alasan CNT dapat menjadi aditif ideal untuk nanokomposit polimerik [39]. MWCNT telah sering dimanfaatkan dalam material komposit untuk meningkatkan sifat listrik dan kinerja mekanik komposit. Dibandingkan dengan bahan penguat tradisional seperti serat kaca, CNT jauh lebih efisien dalam meningkatkan sifat komposit karena rasio aspeknya yang sangat tinggi [40]. 
Tetapi, CNT pun memiliki kelemahan yaitu sifat dispersi partikel yang buruk dan interaksi antar muka yang lemah antara nanopartikel dan matriks polimer [37]. Dispersi CNT menjadi polimer sulit dilakukan karena banyak faktor seperti ketidakmampuan untuk berinteraksi dengan polimer dan bundling yang melekat pada tabung karena adanya gaya van der Waal yang kuat di antara permukaan tabung [41]. CNT murni tidak larut dalam pelarut organik dan cenderung membentuk agregat karena energi permukaan yang sangat tinggi, menyebabkan dispersi heterogen dalam matriks polimer dan memiliki efek negatif pada sifat komposit yang dihasilkan [42]. .Selain itu, morfologi tabung membantu efek bundling karena struktur seperti tali panjang terjalin menciptakan jaringan luas dari tabung yang terikat erat. Jaringan ini tidak mudah dipisahkan dengan cara mekanis. Beberapa metode telah dilakukan untuk memutus jarring ikatan, seperti sonikasi dan homogenisasi untuk menyebar CNT; fungsionalisasi CNT yang dapat mengubah sifat listrik dan mekanik; dan penggunaan surfaktan. Pendekatan alternatif lain untuk dispersi CNT adalah penggunaan polimer dan molekul lain yang tertarik ke permukaan tabung nano dan berbaring di sepanjang permukaan atau membungkus tabung [43].

Modifikasi permukaan secara non-kovalen dan kovalen telah digunakan untuk fungsionalisasi CNT. Meskipun demikian, modifikasi permukaan kovalen dapat dikontrol dengan lebih baik untuk menghasilkan nanomaterial yang lebih stabil. Biasanya, langkah pertama dalam metode ini adalah memasukkan gugus asam karboksilat. Pada langkah kedua, gugus asam karboksilat diaktivasi dengan ionil klorida $\left(\mathrm{SOCl}_{2}\right)$ dan kemudian secara kovalen mengikat setiap molekul yang mengandung gugus amina bebas seperti etilen diamina [44]. Umumnya dilakukan dengan cara menambahkan gugus fungsi seperti - $\mathrm{COOH}$ atau -OH pada CNTyang diturunkan oleh oksidasi dari nanotube karbon. Pendekatan lain telah diusulkan untuk dispersi homogen CNT dalam matriks polimer, termasuk suspensi langsung CNT dalam larutan polimer melalui sonikasi, polimerisasi in situ dengan adanya CNT, dan pemrosesan polimer CNT yang dibantu surfaktan [45].

Untuk meningkatkan dispersi heterogen dalam matriks polimer, Ausman et al. [46] memperkenalkan CNT yang berfungsi secara kimiawi, yang diperoleh dengan pengolahan asam campuran kuat. Gugus karboksil pada CNT termodifikasi yang dihasilkan, diharapkan meningkatkan interaksi antar muka antara matriks polimida dan CNT. Hal ini akan bermanfaat bagi dispersi CNT yang homogen dalam matriks polimer. Wang et al. [47] melaporkan pada penelitian graphene oksida@carbon nanotube (GO/CNT) dapat diperkuat dengan polimida (PI) melalui penautan silang antara ikatan amida, dispersibilitas nanopartikel dalam matriks polimida dapat ditingkatkan dan interaksi antar muka nanopartikel dan matriks PI dapat meningkat.

Park et al. [48] melakukan penelitian dengan proses dua langkah untuk menyiapkan film komposit PI/ MWCNT yang mengandung dari $0 \mathrm{wt} . \%$ hingga $2.0 \mathrm{wt} . \%$ MWCNT. Pada tahap pertama, polimer asam amida disintesis dan kemudian CNT ditambahkan ke polimer yang telah disiapkan. Campuran kemudian diaduk dan dituang untuk membentuk film. Hasil penelitian menunjukkan bahwa resistivitas listrik komposit polimida-MWCNT mengalami penurunan seiring dengan peningkatan kandungan MWCNT yang ditambahkan. Min et al. [49] membuat polimer komposit PI-MWCNT dengan diawali fungsionalisasi amino $\left(\mathrm{NH}_{2}\right)$ pada MWCNT. Selanjutnya, pembentukan polimer dilakukan dengan merendam MWCNT dalam N,N-Dimethylacetamide (DMAc) yang didispersi ultrasonik selama 1 jam pada suhu kamar, diikuti penambahan 4, 4-oxidianiline (ODA). Campuran diaduk dalam penangas es selama 15 menit di bawah atmosfer nitrogen, ditambahkan Pyromellitic dianhydride (PMDA) ke dalam larutan campuran secara perlahan. Campuran diaduk selama 30 menit untuk mendapatkan larutan poly(amic acid) sebagai intermediet produk. Setelah itu, larutan poly(amic acid)/ MWCNT terfungsionalisasi $\mathrm{NH}_{2}$ dituang pada cetakan hingga imidasasi selesai. Film nanokomposit lalu dapat diperoleh.

\section{Kesimpulan}


Carbon nanotubes (CNT) sebagai teknologi nanomaterial unggul membawa sifat mekanik baik seperti konduktivitas termal tinggi, modulus tinggi, kekuatan yang baik, dan fleksibilitas tinggi. Diantara metode yang sering digunakan untuk sintesis CNT, metode CVD (Chemical Vapor Deposition) merupakan metode yang paling menguntungkan karena memiliki biaya yang rendah, produktivitas tinggi, skalabilitas tinggi dan mudah dikontrol, dapat digunakan untuk substrat yang terpola. Bahan prekursor karbon untuk sintesis CNT mayoritas diambil dari bahan bakar fosil yang tidak bisa diperbaharui. Limbah bahan alam seperti tempurung kelapa menjadi alternatif dengan keunggulan biaya murah, ketersediaan melimpah, dan hemat energi. Aplikasi CNT dalam polimer komposit, misalnya pembuatan polimida-CNT. Polimida mempunyai sifat menarik berupa sifat mekaniknya yang sangat baik, stabilitas termal, dan ketahanan kimia. Ketika digabungkan dengan CNT, akan membentuk komposit luar biasa dengan performa kinerja tinggi.

\section{Referensi}

[1] Weeks M.E., 1968, Discovery of the elements. Journal of Chemical Education

[2] Sutanti R. and Handayani S., 2013, Studi Pengaruh Jenis Dan Komposisi Katalis Pada Proses Pertumbuhan Carbon Nanotube (Cnt) Dengan Metode Catalytic Chemical Vapour Deposition (CCVD). Jurnal Teknologi Kimia dan Industri, 2 (2), 135-47.

[3] McNaught A.D. and Wilkinson A., 1997, Compendium of chemical terminology. vol 1669: Blackwell Science Oxford)

[4] Hidayatullah M. 2016 Studi Fisisorpsi Hidrogen Pada Karbon Aktif Dari Ampas Tebu. Institut Teknologi Sepuluh Nopember Surabaya)

[5] Rahman T., Fadhlulloh M.A., Nandiyanto A.B.D. and Mudzakir A., 2015, Sintesis Karbon Nanopartikel. Jurnal Integrasi Proses, 5 (3).

[6] Yu W., Xiang-Gui N., Xiu-Xi W. and Heng-An W., 2003, Effect of temperature on deformation of carbon nanotube under compression. Chinese Physics, 12 (9), 1007-10. doi: 10.1088/10091963/12/9/315.

[7] Nur A., Paryanto P., Jumari A. and Dyartanti E.R., 2007, Sintesis Karbon Nanotube Dari Etanol Dengan Metode Chemical Vapor Deposition. GEMA TEKNIK Majalah Ilmiah Teknik, 10 (2), 41-6.

[8] Sengupta J. 2018 Handbook of Nanomaterials for Industrial Applications, ed C Mustansar Hussain: Elsevier) pp 172-94.

[9] Meyyappan M., Delzeit L., Cassell A. and Hash D., 2003, Carbon nanotube growth by PECVD: a review. Plasma Sources Science and Technology, 12 (2), 205-16. doi: 10.1088/0963-0252/12/2/312.

[10] Kusworo T.D., Yusufina D. and Atyaforsa A., 2013, Pengaruh Katalis Co dan Fe Terhadap Karakteristik Carbon nanotubes Dari Gas Asetilena Dengan Menggunakan Proses Catalytic Chemical Vapour Deposition (CCVD). Reaktor, 14 (3), 234-41. doi: 10.14710/reaktor.14.3.234-241.

[11] Pratama B.W. and Dwandaru W.B., 2017, Uji Karakteristik Morfologi Fisik dan Kimia Butiran Sub Micron Nanomaterial Dengan Variasi Sumber Karbon Sebagai Alat Filtrasi Sederhana. E-Journal Fisika, 6 (3), 212-21.

[12] Andrews R., Jacques D., Rao A.M., Derbyshire F., Qian D., Fan X., Dickey E.C. and Chen J., 1999, Continuous production of aligned carbon nanotubes: a step closer to commercial realization. Chemical Physics Letters, 303 (5), 467-74. doi: https://doi.org/10.1016/S0009-2614(99)00282-1.

[13] Manawi Y.M., Ihsanullah, Samara A., Al-Ansari T. and Atieh M.A., 2018, A Review of Carbon Nanomaterials' Synthesis via the Chemical Vapor Deposition (CVD) Method. Materials, 11 (5), doi: 10.3390/ma11050822.

[14] Alfarisa S., Abu Bakar S., Mohamed A., Hashim N., Kamari A., Md Isa I., Mamat M.H., Rahman Mohamed A. and Rusop Mahmood M., 2015, Carbon Nanostructures Production from Waste Materials: A Review. Advanced Materials Research, 1109, 50-4. doi: 10.4028/www.scientific.net/AMR.1109.50. 
[15] Shukla B., Saito T., Yumura M. and Iijima S., 2009, An efficient carbon precursor for gas phase growth of SWCNTs. Chemical Communications, (23), 3422-4. doi: 10.1039/B903360M.

[16] Barnard J.S., Paukner C. and Koziol K.K., 2016, The role of carbon precursor on carbon nanotube chirality in floating catalyst chemical vapour deposition. Nanoscale, 8 (39), 17262-70. doi: 10.1039/C6NR03895F.

[17] Wang Z., Shen D., Wu C. and Gu S., 2018, State-of-the-art on the production and application of carbon nanomaterials from biomass. Green Chemistry, 20 (22), 5031-57. doi: 10.1039/C8GC01748D.

[18] Janas D., 2020, From Bio to Nano: A Review of Sustainable Methods of Synthesis of Carbon Nanotubes. Sustainability, 12 (10), doi: 10.3390/su12104115.

[19] Azmina M.S., Suriani A.B., Salina M., Azira A.A., Dalila A.R., Asli N.A., Rosly J., Nor R.M. and Rusop M., 2012, Variety of Bio-Hydrocarbon Precursors for the Synthesis of Carbon Nanotubes. Nano Hybrids, 2, 43-63. doi: 10.4028/www.scientific.net/NH.2.43.

[20] Gohier A., Minea T.M., Point S., Mevellec J.Y., Jimenez J., Djouadi M.A. and Granier A., 2009, Early stages of the carbon nanotube growth by low pressure CVD and PE-CVD. Diamond and Related Materials, 18 (1), 61-5. doi: https://doi.org/10.1016/j.diamond.2008.09.022.

[21] Kwon S.-J., Seo H.-K., Ahn S. and Lee T.-W., 2019, Value-Added Recycling of Inexpensive Carbon Sources to Graphene and Carbon Nanotubes. Advanced Sustainable Systems, 3 (1), 1800016. doi: 10.1002/adsu.201800016.

[22] Quinton B.T., Barnes P.N., Varanasi C.V., Burke J., Tsao B.-H., Yost K.J. and Mukhopadhyay S.M., 2013, A Comparative Study of Three Different Chemical Vapor Deposition Techniques of Carbon Nanotube Growth on Diamond Films. Journal of Nanomaterials, 2013, 356259. doi: $10.1155 / 2013 / 356259$.

[23] Williams P.T., 2020, Hydrogen and Carbon Nanotubes from Pyrolysis-Catalysis of Waste Plastics: A Review. Waste and Biomass Valorization, doi: 10.1007/s12649-020-01054-w.

[24] Liu X., Shen B., Wu Z., Parlett C.M.A., Han Z., George A., Yuan P., Patel D. and Wu C., 2018, Producing carbon nanotubes from thermochemical conversion of waste plastics using $\mathrm{Ni} /$ ceramic based catalyst. Chemical Engineering Science, 192, 882-91. doi: https://doi.org/10.1016/j.ces.2018.07.047.

[25] Endo M., Takeuchi K., Igarashi S., Kobori K., Shiraishi M. and Kroto H.W., 1993, The production and structure of pyrolytic carbon nanotubes (PCNTs). Journal of Physics and Chemistry of Solids, 54 (12), 1841-8. doi: https://doi.org/10.1016/0022-3697(93)90297-5.

[26] Araga R. and Sharma C.S., 2017, One step direct synthesis of multiwalled carbon nanotubes from coconut shell derived charcoal. Materials Letters, 188, 205-7. doi: https://doi.org/10.1016/j.matlet.2016.11.014.

[27] Pambayun G.S., Yulianto R.Y., Rachimoellah M. and Putri E.M., 2013, Pembuatan karbon aktif dari arang tempurung kelapa dengan aktivator $\mathrm{ZnCl} 2$ dan $\mathrm{Na} 2 \mathrm{CO} 3$ sebagai adsorben untuk mengurangi kadar fenol dalam air limbah. Jurnal Teknik ITS 2(1), F116-F20.

[28] Halder G., Khan A.A. and Dhawane S., 2016, Fluoride Sorption Onto a Steam-Activated Biochar Derived From Cocos nucifera Shell. Clean Soil Air Water, 44 (2), 124-33. doi: 10.1002/clen.201400649.

[29] Raveendran K., Ganesh A. and Khilar K.C., 1995, Influence of mineral matter on biomass pyrolysis characteristics. Fuel, 74 (12), 1812-22. doi: https://doi.org/10.1016/0016-2361(95)80013-8.

[30] Rampe M.J., Setiaji B., Trisunaryanti W. and Triyono T., 2011, Fabrication and characterization of carbon composite from coconut shell carbon. Indonesian Journal of Chemistry, 11 (2), 7 doi: 10.22146/ijc.21398. 
[31] Wiratmoko A. and Halloran J.W., 2009, Fabricated carbon from minimally processed coke and coal tar pitch as a carbon-sequestering construction material. Journal of Materials Science, 44 (8), $2097-$ 100. doi: $10.1007 / \mathrm{s} 10853-008-3174-0$.

[32] Rantitsch G., Grogger W., Teichert C., Ebner F., Hofer C., Maurer E.-M., Schaffer B. and Toth M., 2004, Conversion of carbonaceous material to graphite within the Greywacke Zone of the Eastern Alps. International Journal of Earth Sciences, 93 (6), 959-73. doi: 10.1007/s00531-004-0436-1.

[33] Kang Z., Wang E., Gao L., Lian S., Jiang M., Hu C. and Xu L., 2003, One-Step Water-Assisted Synthesis of High-Quality Carbon Nanotubes Directly from Graphite. Journal of the American Chemical Society, 125 (45), 13652-3. doi: 10.1021/ja037399m.

[34] Adewumi G.A., Inambao F., Eloka-Eboka A. and Revaprasadu N., 2018, Synthesis of Carbon Nanotubes and Nanospheres from Coconut Fibre and the Role of Synthesis Temperature on Their Growth. Journal of Electronic Materials, 47 (7), 3788-94. doi: 10.1007/s11664-018-6248-z.

[35] Jiang Q., Tallury S.S., Qiu Y. and Pasquinelli M.A., 2020, Interfacial characteristics of a carbon nanotube-polyimide nanocomposite by molecular dynamics simulation. Nanotechnology Reviews, 9 (1), 136-45.

[36] Roy A., Mu L. and Shi Y., 2020, Tribological properties of polyimide coating filled with carbon nanotube at elevated temperatures. Polymer Composites, 41 (7), 2652-61. doi: 10.1002/pc.25564.

[37] Chao M., Li Y., Wu G., Zhou Z. and Yan L., 2019, Functionalized Multiwalled Carbon NanotubeReinforced Polyimide Composite Films with Enhanced Mechanical and Thermal Properties. International Journal of Polymer Science, 2019, 9302803. doi: 10.1155/2019/9302803.

[38] Kim P., Shi L., Majumdar A. and McEuen P.L., 2001, Thermal Transport Measurements of Individual Multiwalled Nanotubes. Physical Review Letters, 87 (21), 215502. doi: 10.1103/PhysRevLett.87.215502.

[39] Aseel A.K., 2017, Preparation and electrical properties of polyimide/carbon nanotubes composites. Materials Science-Poland, 35 (4), 755-9. doi: https://doi.org/10.1515/msp-2017-0096.

[40] Mo T.-C., Wang H.-W., Chen S.-Y. and Yeh Y.-C., 2008, Synthesis and characterization of polyimide/multi-walled carbon nanotube nanocomposites. Polymer composites, 29 (4), 451-7. doi: $10.1002 /$ pc.20468.

[41] Lin T., Bajpai V., Ji T. and Dai L., 2003, Chemistry of Carbon Nanotubes Australian Journal of Chemistry, 56 (7), 635-51. doi: https://doi.org/10.1071/CH02254.

[42] Kim B.S., Bae S.H., Park Y. and Kim J., 2006, Polyimide/Carbon Nanotubes Composite Films: A Potential for FPCB, 2006 International Conference on Nanoscience and Nanotechnology, 3-7 July 2006, 2150-3605

[43] Delozier D., Tigelaar D., Watson K., Smith Jr J., Lillehei P. and Connell J., 2004, Polyimide/Carbon Nanotube Composite Films for Electrostatic Charge Mitigation.

[44] OKTAY B., TÜRKER S., KARATAŞ S. and APOHAN N.J.J.o.t.T.C.S.S.A.C., 2018, Multi-Walled Carbon Nanotube Reinforced Polyimide Composites. Journal of the Turkish Chemical Society Section A Chemistry, 5 (1), 283-94.

[45] So H.H., Cho J.W. and Sahoo N.G., 2007, Effect of carbon nanotubes on mechanical and electrical properties of polyimide/carbon nanotubes nanocomposites. European Polymer Journal, 43 (9), 37506. doi: https://doi.org/10.1016/j.eurpolymj.2007.06.025.

[46] Ausman K.D., Piner R., Lourie O., Ruoff R.S. and Korobov M., 2000, Organic Solvent Dispersions of Single-Walled Carbon Nanotubes: Toward Solutions of Pristine Nanotubes. The Journal of Physical Chemistry B, 104 (38), 8911-5. doi: 10.1021/jp002555m.

[47] Wang J., Jin X., Wu H. and Guo S., 2017, Polyimide reinforced with hybrid graphene oxide @ carbon nanotube: Toward high strength, toughness, electrical conductivity. Carbon, 123, 502-13. doi: https://doi.org/10.1016/j.carbon.2017.07.055. 
[48] 박수진, Chae S.-W., 이종문 and 강신재, 2010, A Study on Electrical and Thermal Properties of Polyimide/MWNT Nanocomposites. Bulletin of the Korean Chemical Society, 31 (8), 2279-82. doi: 10.5012/BKCS.2010.31.8.2279.

[49] Min C., Liu D., He Z., Li S., Zhang K. and Huang Y., 2018, Preparation of novel polyimide nanocomposites with high mechanical and tribological performance using covalent modified carbon nanotubes via Friedel-Crafts reaction. Polymer, 150, 223-31. doi: https://doi.org/10.1016/j.polymer.2018.07.035. 